\title{
A literatura médica brasileira sobre a peste branca: $1870-1940$
}

SHEPPARD, D. de S.: 'A literatura médica brasileira sobre a peste branca: 1870-1940'. História, Ciências, Saúde - Manguinhos, vol. VIII(1): 172-92, mar.-jun. 2001.

As teorias de Darwin constituem o paradigma escolhido pelos médicos do Sul dos Estados Unidos, quando se debruçaram sobre o tema de diferenças na morbidade e na mortalidade entre as raças após a abolição. Estes médicos teceram considerações sobre a crise de saúde que afetou a população descendente dos africanos naquela região. $\mathrm{O}$ mesmo não se deu com os médicos brasileiros ao tentarem entender e explicar a crise de saúde que afetou a população de descendência africana no seu país. Na verdade, em nenhum dos jornais médicos brasileiros, desde o final da abolição até a década de 1930, pode se encontrar um só artigo onde um médico atribuísse a morbilidade ou mortalidade de seus pacientes negros ou dos negros em geral, a qualquer fonte que usasse um paradigma racial como referência. Os psiquiatras e os médicos eugenistas foram exceção.

PALAVRAS-CHAVE: médicos, raça, darwinismo racial, tuberculose, negros.

white plague: 1870-1940

Tradução: Marta de Almeida

\section{Dalila de Sousa Sheppard}

350 Spelman Lane, SW, PO Box 250

Atlanta, GA 30314 USA

ddesousa@spelman.edu
SHEPPARD, D. de S.: 'Brazilian medical literature about the white plague: 1870-1940'.

História, Ciências, Saúde - Manguinhos, vol. VIII(1): 172-92, Mar.-June. 2001.

The Darwinian theories compound the paradigm adopted by the physicians in Southern United States, when they turned to the subject of the differences in morbidity and mortality among the races after abolition. These physicians engaged in thoughts about the health crisis that assaulted the African-American population on that region. The Brazilian physicians, on the other hand, would not try to understand or explain the health crisis that overtook the population descended from Africans on their country. Actually, not a single Brazilian medical journal, since the end of abolition to the 1930s, published an article where a physician indicated the morbidity and mortality of his negro patients, or of negroes in general, as caused by any source related to a racial paradigm. The psychiatrists and eugenicist doctors were exceptions.

KEYWORDS: physicians, race, racial Darwinism, tuberculosis, negroes. 
$\mathrm{A}^{\mathrm{s}}$ s teorias de Darwin constituem o paradigma escolhido pelos médicos do Sul dos Estados Unidos, quando se debruçaram sobre o tema de diferenças genéticas entre as raças após a abolição da escravatura. Estes médicos teceram considerações sobre a crise de saúde que afetou a população descendente dos africanos naquela região. $\mathrm{O}$ mesmo não se deu com os médicos brasileiros ao tentarem entender e explicar a crise de saúde que afetou a população de descendência africana no seu país. ${ }^{1} \mathrm{Na}$ verdade, em nenhum dos jornais médicos brasileiros, desde o final da abolição até a década de $1930,{ }^{2}$ pode se encontrar um só artigo onde um médico atribuísse a morbilidade ou mortalidade de seus pacientes negros, ou dos negros em geral, a qualquer fonte que usasse um paradigma racial como referência.

Os médicos no Brasil mantiveram-se totalmente indiferentes ao paradigma racial como um tópico de interesse científico ou intelectual. Por exemplo, das 110 entradas do Dicionário Biobibliográfico Brasileiro de Escritores Médicos (1500-1899) de Orsini Giffoni, nem um só título inclui o verbete "negro". Também o Índice-Catálogo Médico Paulista, 1860-1936, de José Andrade Maia, apresenta somente quatro trabalhos sobre raça, e cinco sobre negros. Além disso, em nenhum dos 73 trabalhos sobre tuberculose, 217 sobre lepra e 128 sobre sifilis, incluiuse qualquer referência a "negros" nos títulos. ${ }^{3}$

\section{Os médicos 6rasileiros interpretam a tuberculose}

A pesquisa da literatura médica publicada no Brasil durante o período mencionado mostra que um paradigma ambiental foi o escolhido para explicar o aumento do índice de morbilidade e mortalidade nas chamadas "classes pobres". A tuberculose foi a doença escolhida como estudo de caso no Brasil porque foi uma das doenças de efeito mais devastador nestas "classes". 4

A incidência de tuberculose no Brasil cresceu indubitavelmente desde 1850, mas só em 1868 Otto Wücherer, um dos mais famosos médicos no Brasil, levantou a questão de qual seria a causa de tal incidência. Ele condenou a noção européia ainda predominante de que a doença era rara nos trópicos. Ele reconheceu que era uma doença tida como das cidades e achava que os mais suscetíveis a ela teriam herdado tal suscetibilidade. $O$ fator mais importante a favorecer esta suscetibilidade, segundo ele, era a deterioração do meio de vida da maior parte da população, devido, segundo ele afirmava, à impossibilidade do preço da mão-de-obra manter-se em igualdade de condições com o custo de vida. $\mathrm{O}$ aumento da freqüência da doença, neste caso, seria resultante do aumento do número de pessoas empobrecidas. ${ }^{5}$

Dez anos mais tarde, o médico Alves da Silva, ao escrever sua tese para a Faculdade de Medicina do Rio de Janeiro, expressou horror com o crescente dano que a tuberculose vinha causando na população 
daquela cidade. Ele argumentou que a doença era endêmica no Rio de Janeiro, citando causas bastante específicas para o fenômeno. Primeiramente, culpava a pobreza, ao afirmar que "a doença tinha uma predileção pelos pobres”. Ele acreditava que a falta de higiene e de nutrição apropriada eram as causas principais da tuberculose. Mais do que isso, argumentava ele, "dieta sem nitrogênio aumentava a suscetibilidade das pessoas à doença". Alves da Silva considerava "a dieta da classe pobre urbana tão deficiente que não dava para compensar as perdas orgânicas diárias, causadas pelo trabalho árduo e pelo calor excessivo”. Assim é que os habitantes dos cortiços do Rio tornavamse especialmente vulneráveis. Ele também achava que a tuberculose era muito destrutiva na "classe escrava", o que não o surpreendia, pois as condições de vida dos escravos eram as mesmas da classe pobre urbana. ${ }^{6}$

No ano de 1880, a escrófula foi considerada, pela primeira vez, uma forma de tuberculose. $\mathrm{O}$ dr. Francisco da Rocha Lima, filho de um dos mais respeitados médicos da Bahia, utilizou-se da argumentação apresentada a seguir na sua tese de doutoramento. Lima achava que esta forma de tuberculose era causada pela pobreza, má nutrição e o ar abafado inalado pelos que moravam em lugares de superpopulação.

Foi somente depois da descoberta do bacilo de Koch e após a virada do século XX, que o grande volume de trabalhos sobre tuberculose começou a aparecer no Brasil. A maior parte desta literatura discutia a suscetibilidade do pobre à doença; ocasionalmente havia alguma referência específica às pessoas negras. $\mathrm{O}$ dr. Victor Godinho (1904, pp. 76-85), um dos diretores da Revista Médica de São Paulo, referiu-se à tuberculose como "a praga do pobre". Ele culpava as moradias lotadas, a falta de higiene e nutrição deficiente por esse fenômeno.

São Paulo, contudo, não era uma das cidades mais atingidas pela praga da tuberculose. Na verdade, a mortalidade devido à tuberculose diminuíra no começo do século XX. Mais tarde, o argumento era que a tuberculose diminuíra "porque o número de negros diminuíra". De fato, os negros trazidos para trabalhar nas fazendas de café, de acordo com o censo de 1880 e 1890, "estavam rapidamente sendo substituídos pelos italianos e outros imigrantes europeus, que vieram trabalhar nas plantações num sistema de cooperativa". ${ }^{8}$

Em 1905, Azevedo Lima (1905, pp. 223-4), médico do Rio de Janeiro e presidente da Liga Brasileira contra a Tuberculose, observou que a doença atacava o pobre como uma combinação de "forças sociais": "casas sujas e insalubres, nutrição deficiente, alcoolismo, trabalho excessivo, em suma todas as condições que abatem o organismo e lhe tiram a resistência”. Ele conhecia as idéias de Darwin, que haviam sido usadas para explicar a suscetibilidade dos negros à doença em outros países (especialmente nos Estados Unidos). Azevedo Lima achava que a tuberculose não era uma doença mandada providencialmente para enfraquecer os pobres e inúteis, pois também levava os "fortes e hábeis". 
Em 1907, o dr. Mariano Dias, do Rio de Janeiro, fez suas as palavras dos seus predecessores sobre má nutrição e residência insalubre como fatores que predispunham à tuberculose: a pobreza criava condições para a doença. Ele argumentou, ainda, ser somente pobreza e não raça que predispunha uma pessoa a contraí-la, bem como a freqüência com que se expunha à doença. Sendo assim, aqueles que freqüentavam igreja, teatro e outros ajuntamentos públicos correriam maior risco de contrair tuberculose, se comparados aos que não freqüentavam lugares de grande concentração humana.

Sintetizando, na virada do século, os médicos brasileiros não consideravam raça um fator válido em suas explicações sobre a alta mortalidade dos negros vitimados pela tuberculose. A descoberta do bacilo de Koch precipitou uma série de 33 artigos na Gazeta Médica sobre a destruição causada pela tuberculose na Bahia durante as décadas de 1880 e 1890 . Em todos os casos, os artigos discutiam a etiologia da doença ou sugeriam tratamento. Jamais o quesito raça foi considerado na etiologia da doença, mesmo quando estatísticas sobre negros ou mulatos eram apresentadas. Lembremo-nos que a Bahia era o estado com a maior percentagem de negros em sua população. Durante o período entre 1870 e 1910 , as revistas médicas do Rio de Janeiro evidenciaram a mesma postura de não considerar raça como um elemento das discussões em torno da mortalidade pela tuberculose. $\mathrm{O}$ mesmo se deu em São Paulo. Foi somente em 1907 que o dr. Mariano Dias tornou-se o primeiro médico a considerar raça como uma variante de alta suscetibilidade à tuberculose. Ainda assim, ele imediatamente descartou o argumento usado em prol da explicação ambiental em voga (Sant'Anna e Teixeira, 1984).

A aparente falta de pesquisa médica em assuntos relacionados à raça parece significativa, já que os médicos brasileiros achavam-se familiarizados com o trabalho de Darwin. Na verdade, já nos idos de 1866, na primeira edição da Gazeta Médica da Bahia (pp. 128-31), o dr. Otto Wücherer discutiu o tema 'darwinismo e medicina' enquanto analisava um discurso proferido meses antes por um médico americano, o dr. Benjamin E. Cotting na Sociedade Médica de Massachusetts.

$\mathrm{O}$ artigo do dr. C. Richet publicado em 1873 na Gazeta Médica (pp. 108-10, 122-4) mostra claramente que os médicos brasileiros conheciam não só o trabalho de Darwin, como também o debate que o precedeu entre monogenistas e poligenistas dos Estados Unidos no período préabolição.

Tanto os médicos do Rio como seus colegas da Bahia tinham conhecimento de Darwin e suas teorias. Em 1875, o dr. Augusto César de Miranda Azevedo organizou, no Rio de Janeiro, a 'Conferência popular sobre o darwinismo'. Em meados da década de 1890, um volume intitulado Mulheres em sociogenia, foi publicado após sua morte. Ambos demonstravam a influência darwinista, mas, ainda assim, não continham referências aos negros (Maciel de Barros, 1986, p. 14). 
$\mathrm{Na}$ história do pensamento brasileiro do final do século XIX e começo do século XX, apenas cinco indivíduos - Tobias Barreto, Luís Pereira Barreto, Tito Lívio de Castro, Guedes Cabral e Silvio Romero eram darwinistas reconhecidos. Considere-se também que, com exceção de Silvio Romero, tido como darwinista social, os demais eram médicos. Repetindo, exceto por Silvio Romero (um dos maiores e mais estridentes defensores da tese de branqueamento), ninguém havia escrito sobre problemas relativos à raça. ${ }^{9}$

Parece claro que os médicos brasileiros tiveram oportunidades, por um lado, de se deixar influenciar pelos preceitos biodeterministas raciais de Charles Darwin, tal como seus colegas nos Estados Unidos, e, por outro, de formular uma teoria baseada na raça. Seus conhecimentos também foram substanciados por artigos publicados nos periódicos especializados. Além disso, graças ao trabalho dos médicos da Escola Baiana de Medicina Tropical, soube-se que certas doenças foram trazidas da África para o Brasil pelos escravos. Havia até uma doença, o ainhum, considerada pelos médicos da Bahia e do Rio exclusivamente como "doença dos negros". ${ }^{10}$

Sendo assim, apesar da inexperiência dos médicos brasileiros a respeito da saúde dos escravos, estes pareciam partilhar a noção de que havia doenças específicas aos negros. Em seu estudo da doença em 1944, Xavier Sigaud (1844) fez um esforço para convencer os médicos brasileiros sobre as doenças peculiares dos negros. Além disso, a comunidade médica brasileira mantinha contato com a medicina européia e norte-americana: as revistas médicas brasileiras divulgavam listas das revistas e publicações prestigiadas naqueles continentes. Ainda assim, os médicos brasileiros abstiveram-se totalmente de discutir as questões relativas a "particularidades biológicas dos negros", tão em moda nessas partes do mundo. Também se abstiveram de aceitar essas tão faladas peculiaridades raciais da população de descendência africana. ${ }^{11}$

Certamente, na medida em que os médicos brasileiros se viam como os guardiães da saúde da nação, este fato por si só seria razão suficiente para uma tomada de posição sobre os problemas relativos à raça, mesmo porque os negros brasileiros enfrentaram problemas graves de saúde, semelhantes - e, em alguns casos, mais severos - aos dos americanos nas décadas que sucederam a abolição da escravatura. Contudo, durante os cinqüenta anos aqui pesquisados, e a despeito de certos incentivos, os médicos brasileiros, tanto da região Nordeste predominantemente negra, como das regiões Central e Sul, mantiveramse à parte do círculo de estudiosos brasileiros que foram influenciados pelas teorias raciais européias. Conseqüentemente, também mantiveramse afastados do círculo de darwinistas raciais que viam o escravo africano e seus descendentes como prejudicial ao bem-estar racial, físico e mental do país. ${ }^{12}$ 


\section{Os médicos brasileiros escrevem sobre a tuberculose: 1918-39}

Foi só em 1917 que apareceram artigos nos jornais médicos brasileiros caracterizando raça como uma variante definida na suscetibilidade à tuberculose. Tal posição foi a regra, e não a exceção, durante o período da guerra. $\mathrm{O}$ dr. R. Carneiro, diretor do Ambulatório Pediátrico do Hospital-Maternidade do Rio, escreveu sobre o alto índice de tuberculose entre a juventude brasileira, freqüência revelada pela reação ao teste de Pirquet. Ele comentou que $70 \%$ das vítimas da tuberculose eram da raça negra e prosseguiu observando que os negros cuidavam dos brancos. A mensagem era clara: crianças brancas achavam-se em perigo de contrair uma doença que grassava entre os empregados negros e alguma coisa deveria ser feita para protegê-las. Os médicos, então, fizeram soar um alarme semelhante ao dos médicos americanos algumas décadas antes. O dr. Carneiro (1917, pp. 792-4) prosseguiu, sugerindo que as crianças saudáveis deviam ser separadas das doentes nas escolas.

$\mathrm{O}$ dr. Carneiro, contudo, logo contemporizou seus comentários alarmistas (talvez na tentativa de acalmar os pais abastados de seus pacientes). Ele acrescentou que "o crescimento da praga branca se dava entre crianças da classe pobre”. Pobreza, concluiu ele, era a raiz do problema, e especialmente a má nutrição resultante da pobreza. Ele citou estudos para mostrar que, aqueles cuja dieta incluía gordura suficiente, eram muito mais resistentes à fúria da tuberculose do que os pobres cuja dieta era baseada em hidratos de carbono.

Outra referência, que já era parte da literatura, dizia respeito ao vínculo entre a tuberculose e os negros nos Estados Unidos. A suscetibilidade do mulato tornou-se assunto da literatura médica brasileira em 1917. Num artigo dirigido ao presidente do Brasil, publicado no Rio pelo médico brasileiro dr. Plácido Barbosa (1917, pp. 270-1), ele argumentou que o Rio tinha o mais alto índice de mortalidade por tuberculose, que "devia-se sem sombra de dúvida, a baixa resistência das massas, massas estas constituídas em grande parte por mestiços, que demonstram uma extraordinária fragilidade à tuberculose”. ${ }^{13}$

Embora Barbosa (op. cit., I: 251-3, II: 260-3, III:269-71) fosse um dos primeiros a mencionar o conceito de suscetibilidade racial à doença, ele não se ateve a esse fato, como os seus predecessores no Brasil. Ele mostrou-se ambivalente, também atribuindo o alto índice de mortalidade à diminuta resistência à doença, causada por má nutrição e pela "ampla disseminação do contágio pelo tubérculo”, deflagrada por uma higiene precária e recursos de saúde pública deficitários.

Numa monografia de 1918 sobre a campanha contra a tuberculose no Brasil, o dr. Azevedo Sodré, diretor do Brasil-Médico e professor de patologia interna da Faculdade de Medicina do Rio de Janeiro, também demonstrava ambivalência em suas explicações a respeito dos índices de mortalidade causados pela tuberculose. Ele argumentava que a tuberculose era "mais danosa precisamente naquelas cidades onde o 
contingente de negros e mulatos era maior". Ele também referia-se especificamente à "suscetibilidade exagerada dos mestiços e negros em contrair a doença”. Ainda assim, a ambivalência aparece quando ele atribui "a qualidade letal da doença a outros fatores, tais como o clima, trabalho excessivo, alcoolismo e práticas de higiene inadequadas”. ${ }^{14}$

O ano de 1918 presenciou o avanço de outro argumento racista sobre a mortalidade dos negros pela tuberculose. Saneamento do Brasil, de Belisário Penna (1918, pp. 8,15) foi um libelo que excedeu em intensidade os anteriores. Suas conclusões lembravam as dos médicos americanos advindas do período da peste negra posterior à escravidão. Assim é que Penna, um dos fundadores da Liga de Saneamento do Brasil, fez um levantamento da população negra no Brasil e concluiu tristemente que ela estava sendo "devastada" não somente pela tuberculose, mas também pela sífilis, doença de Chagas, filária e vermes. Ao contrário de seu colega Azevedo Sodré, o dr. Penna argumentava que a culpa das doenças dos negros devia-se aos seus traços morais. Ele dizia que, como escravos, os negros haviam sido submetidos a "uma disciplina de trabalho forçado", e em retorno, eram mantidos relativamente bem nutridos, tinham roupa e casa. Com a abolição, contudo, "centenas de milhares de indivíduos ignorantes" tornaram-se livres para se espalhar em todas as direções e caíram nos vícios do "alcoolismo e orgias". Resumindo, eles rapidamente retornaram a um “estágio selvagem” e, como conseqüência, tornaram-se anêmicos e mais suscetíveis à doenças.

Ainda assim, Belisário Penna demonstrava a mesma ambivalência racial de seus colegas. Enquanto repetia incessantemente que a falta de moral dos negros era a causa de sua suscetibilidade à doença, ele se contradizia dizendo que os negros não deveriam ser culpados por seus problemas de saúde. Na verdade, a solução para a melhora da saúde de todos os brasileiros decorreria de melhoria no sistema sanitário e acompanhado de melhor nutrição. A confusão do dr. Penna parece advir da sua impossibilidade de distinguir os argumentos biológicos dos morais.

O ano de 1918 marca um ponto de transição na percepção, por parte da comunidade médica brasileira, da etiologia da doença que mais afligia o país. Até então, haviam sido atribuídas razões puramente ambientais à maior parte dos padrões de morbilidade e mortalidade brasileiros. De 1918 em diante, os médicos começaram a se ater, de uma maneira crescente, à raça como explicação da incidência de tuberculose entre parte da população.

É necessário aventurar-se além de 1918 - a época em que os médicos dos Estados Unidos parecem ter abandonado o jargão darwinista em seus artigos sobre as dificuldades dos negros na área da saúde - para se certificar de que esta tendência se tornaria uma teoria racista na acepção da palavra. Se tal era o caso, então, significaria uma completa aceitação dos preceitos racistas darwinistas pela comunidade 
médica brasileira do Rio de Janeiro e da Bahia, e também de algumas revistas sobre tuberculose publicadas por institutos de tuberculose espalhados pela nação. Estas foram publicadas entre 1918 e meados da década de 1940. Os títulos e o conteúdo dos artigos das revistas médicas publicadas nestas cidades indicam que os médicos brasileiros tinham se sensibilizado a respeito dos problemas de morbilidade e mortalidade diferenciais entre as raças.

Isto não quer dizer que os médicos nestas comunidades tivessem se convertido ao racismo científico em geral ou darwinista em particular. ${ }^{15}$ $\mathrm{Na}$ verdade, havia apenas alguns poucos exemplos de postura racial nas explicações médicas em relação à experiência de doenças diferentes entre as raças do Brasil depois de 1918. A maior parte dos médicos que mencionava raça fazia-o dentro do contexto reinante da etiologia da doença. Assim é que, até 1940, as explicações de diferenças raciais envolviam um dos princípios da teoria do germe: o tempo de exposição que uma raça em particular tinha em relação a uma doença determinava a habilidade dessa raça em resistir ou combater a infeção com sucesso - uma explicação ambiental, baseada na experiência.

Alguns médicos acrescentaram adendos inesperados a este argumento baseado em causas ambientais, para explicar a evidente suscetibilidade dos negros à tuberculose. O dr. Antonio Ferrari (1929, pp. 233-5), por exemplo, na sua palestra 'Epidemiologia da tuberculose sob o ponto de vista brasileiro', proferida na sessão de 4 de julho de 1929, do Segundo Congresso Pan-Americano da Tuberculose, publicada nas atas do mesmo congresso, declarou que a raça negra podia ter desenvolvido resistência à infeção pela tuberculose, mas as condições das plantações destruíram suas chances. Seu ponto de vista associa ambiente e hereditariedade:

Os escravos africanos, que habitavam lugares imundos, superpovoados e de grande promiscuidade, foram devastados pelas doenças

a ausência de cuidados médicos efetivos, agravada por nutrição deficiente, e o estado etílico dos escravos, geralmente intoxicados por alcoolismo. (Tudo isso) destruiu a resistência da raça à doença. Esta raça, desde o início, já era congenitamente suscetível.

Por todas estas razões, Ferrari achava que "a raça africana era um campo fértil” para a tuberculose se incubar, florescer e se expandir, já que as condições de vida das grandes cidades industriais brasileiras, onde os negros viviam, eram uma réplica da vida nas plantações. Ele acrescenta que os brancos não foram atingidos pela doença com a mesma intensidade: "A tuberculose, como outras doenças infecciosas, quando (sic) atacam uma raça por muitos séculos, preparam no organismo daquela raça fatores orgânicos de defesa contra o ambiente (da doença) uma conseqüência da lei biológica de preservação da espécie." 
Uma vez mais, a visão reinante relacionava os fatores biológicos aos fatores baseados em observação da doença.

Outra divergência na aplicação da teoria da suscetibilidade dos negros à tuberculose apareceu no final da década de 1930, formulada por um dos fundadores do Instituto para o Estudo da Tuberculose (Instituto de Tisiologia) na Bahia. Num trabalho apresentado no Primeiro Congresso Brasileiro sobre a Tuberculose, que mais tarde foi publicado nos Arquivos do Instituto Brasileiro de Tuberculose (1939, pp. 779, 867), o dr. José Silveira mostrava-se perplexo com o alto índice de suscetibilidade à tuberculose, ainda manifestada pelos negros. Ele argumentava que, na Bahia, os negros tinham tido "contato com a civilização por muitos anos”, pois tinham vivido na cidade e na periferia "em total promiscuidade com os mulatos e brancos". Ainda assim, "a reação mais violenta à tuberculose foi observada nos negros, com uma freqüência duas vezes mais intensa do que a dos brancos e mulatos". Ainda mais, a tuberculose continuava se espalhando no interior por causa da "falta de resistência" do "segmento negro da população".

Estas observações fizeram com que Silveira rejeitasse a teoria de que a imunidade fosse adquirida geração após geração, com a continuidade do contato com a doença. Ele também não aceitou o argumento oposto, de que os negros, com o passar do tempo, tivessem perdido a resistência à tuberculose, nem tampouco se convenceu pelos colegas que consideravam os fatores ambientais totalmente responsáveis pela suscetibilidade dos negros a essa doença. Seu ponto de vista era um tipo de síntese que atribuía a suscetibilidade negra à tuberculose a um conjunto de fatores ambientais, tais como habitação deficiente, com muitas pessoas, nutrição inadequada, falta de educação sanitária e mais "uma peculiaridade morfológica e biológica da raça". Contudo, ele não se mostrou interessado em especular sobre a natureza desta peculiaridade, mas propôs que se pesquisasse mais sobre o assunto.

$\mathrm{Na}$ verdade, não havia necessidade de mais pesquisa. Silveira apresentou em seu trabalho a razão para os contínuos altos índices de infeção e mortalidade causada pela tuberculose entre os negros. Ele mencionou que as estatísticas do instituto indicavam que o "sistema linfático dos negros (estava) constantemente sofrendo agressão (do bacilo tubérculo e que o resultado era visível) na extensa caseação dos gânglios acompanhada por disseminação hematógena”. Esta descrição assinalava o progresso da doença quando primeiro atacava as pessoas. Finalmente, deve-se observar a perda de fé dos médicos na teoria do germe como uma explicação viável para as dificuldades que os negros baianos experimentavam com a tuberculose, baseada na observação dos negros que viviam naquela cidade por "muitos anos". É um fato conhecido que, do ponto de vista atual, a aquisição de resistência ao bacilo tubérculo é um processo que leva, no mínimo, um século. ${ }^{16}$

Convém notar que os artigos dos médicos brasileiros nos idos de 1930, tanto como seus colegas do final das décadas de 1910 e 1920, 
continuaram ambivalentes em sua interpretação da morbilidade e mortalidade pela tuberculose. A postura primária dos argumentos médicos, contudo, havia migrado de uma visão ambiental (com algumas considerações de raça) para uma maior visão de raça (mas não racista), complementada por considerações ambientais.

Menos ambivalente foi o diretor do Hospital da Tuberculose de Belém, capital do estado do Pará, num trabalho datado de 1939. O dr. Henrique Esteves (1939, pp. 563-6) considera a noção, tida como verdadeira, de que a imunidade era desenvolvida gradualmente por uma nova raça em contato com tuberculose. Ele argumentava que, no caso dos negros, a tese de imunidade adquirida deveria ser descartada. Ele propunha que, em vez disso, a "fragilidade observada" à doença deveria ser vista como "uma falta de imunidade devida a uma composição bioquímica que fez do seu corpo um campo fértil para o crescimento do (tubérculo) bacilo".

Orlando Cabral Motta, diretor do Sanatório de Tuberculose em Belo Horizonte, concordava com esta posição. Em um artigo publicado no Brasil-Médico em 1940 (pp. 323-4), ele declara que "com o passar dos anos, os negros não conseguiram adquirir a mesma imunidade à tuberculose obtida pelos brancos". Ele reconhece que fatores ambientais deficientes podiam causar uma incidência maior. Ele não acha, porém, que fatores socioeconômicos expliquem as diferenças fundamentais entre brancos e negros na sua experiência com a doença nem que estes fatores pudessem explicar por que a doença se deu de maneira substancialmente diferente entre os negros. Ele sugere, sim, que as razões para tão importante diferença estaria centrada nos atributos raciais dos negros.

Parece bastante claro que os médicos do período entre as duas guerras mostravam-se ambivalentes quanto à natureza "dos atributos raciais" dos negros. No entanto, é preciso notar que a maioria destes estudos do período pós-1918 incluía sempre uma interpretação racial nas suas análises sobre os altos índices de morbilidade e de mortalidade por tuberculose dos negros. Por outro lado, neste mesmo período foram publicados estudos que ignoraram a ênfase racial. Por exemplo, Amaury Medeiros (1920) apontou para a nutrição deficiente e desequilibrada, assim como a falta de educação e de instrução, como os maiores cúmplices pela "alarmante" mortalidade por tuberculose das classes pobres. Até na década seguinte, podem-se encontrar exemplos claros de médicos que não adotaram posturas raciais em suas análises. O dr. J. F. Domingues Carneiro (1934, pp. 800-6), por exemplo, escreveu sobre as causas da suscetibilidade à tuberculose em termos de clima e dieta sem referência nenhuma à raça. Na maioria dos casos, afirmamos que os médicos brasileiros do período entre as grandes guerras se achavam divididos entre rezar por uma postura racial ou uma ambiental, mas geralmente se inclinavam pela primeira.

Esta ambivalência é ilustrada nos artigos de Octavio de Freitas, desde o final do século XIX até 1940. Freitas manteve-se no posto de 
presidente da Liga Pernambucana contra a Tuberculose, durante a maior parte de sua carreira, e foi um escritor prolífico no que se refere à tuberculose. Num estudo de 1939 (pp. 551-2, 555), Freitas argumentava, apresentando estatísticas indicativas, que eram os brancos, e não os negros, as maiores vítimas da tuberculose em Pernambuco, nos idos de 1894 e entre 1919 e 1923. Ele acrescentava que seus dados estatísticos mostravam que a morbilidade e mortalidade dos negros por tuberculose, na capital de Pernambuco, apresentara um declínio significativo durante a década de 1930. Freitas atribuiu o declínio à melhoria das condições econômicas que os negros usufruíam na cidade. Estas estatísticas, contudo, representavam apenas o número de morte por raça para o estado de Pernambuco, durante aquele período e não os índices de morte por raça. Assim sendo, estes índices poderiam esconder mais do que revelar.

Num artigo publicado em 1940 (pp. 165-6), onde repetia muitos dos dados apresentados em estudos anteriores, Freitas admitiu que o grosso da opinião médica via os negros como mais suscetiveis que os mulatos à tuberculose, e os mulatos, por sua vez, mais suscetíveis que os brancos. De fato, ele substanciou seus artigos com estatísticas que provavam esta hierarquia imunológica. $\bigcirc$ médico, contudo, não considerou os próprios dados como válidos e duvidou que os negros tivessem maior suscetibilidade à tuberculose. Em sua opinião, tal suscetibilidade não podia ser provada até que os métodos de coleta de dados estatísticos no Brasil se tornassem mais precisos.

Freitas (1940, p. 168, grifos do autor) então se contradisse argumentando que "os negros virgens", isto é, os recém-chegados ao Brasil, provavelmente "contraíam a doença com maior intensidade". Ele explicou que, quando "eles chegavam, os negros ainda não haviam se contaminado pela praga branca, e só se contaminavam com o contato com os imigrantes infestados de tuberculose vindos de Portugal e outros países europeus". Freitas então argumentou que a inabilidade dos negros em lutar contra a doença tinha sido "agravada pelas condições sociais e de higiene das senzalas onde eles viviam".

Mas logo Freitas avança a posição de que as populações nascidas no Brasil, resultante de miscigenação, revelam "um nível similar de resistência ao nível dos brancos". Ele afirma que: "A mistura de ambas as raças trouxe consigo mais do que uma sub-raça de mestiços. Também serviu para diluir, mais e mais, o número e virulência dos germes responsáveis por contaminação daqueles já doentes.”

Estas condições, concluiu ele, equalizaram-se entre as duas raças no que diz respeito à suscetibilidade à tuberculose.

As conclusões contraditórias de Octavio de Freitas, em seus estudos de etiologia e raça referentes à tuberculose no Brasil, refletem a confusão a respeito dos argumentos com que os médicos brasileiros se referiam a estes temas, após a Primeira Guerra Mundial. Tais estudos, ao contrário dos que os precederam, consideraram raça como uma variante, no que 
se refere à questão da suscetibilidade à doença. Ainda assim, seus autores mostravam-se relutantes em marginalizar os fatores ambientais, e opuseram-se a interpretações racistas.

Assim é que até após 1918, os médicos brasileiros continuaram a evitar explicações racistas para o aumento da mortalidade por tuberculose entre os negros. Em vez disso, chegaram a um consenso de que o ambiente onde viviam os negros, junto com fatores imunológicos, seria responsável pela crise de saúde dos negros.

\section{Alternativas ao darwinismo propostas pela classe médica}

$\bigcirc$ fato de que a maioria esmagadora dos médicos brasileiros não escolheu um escopo racista nas suas análises fez com que os que haviam se convertido ao racismo científico ficassem em evidência. Durante os cinqüenta anos que decorreram entre o fim da abolição e o início da Segunda Guerra Mundial (1888-1939), dois grupos em particular destacaram-se pelas posturas racistas em relação aos negros. $\mathrm{Na}$ verdade, tanto os psiquiatras da Escola de Medicina Legal da Bahia como os eugenistas da Faculdade de Medicina de São Paulo foram influenciados se não por Darwin, então por seu primo Francis Galton, assim como por outros europeus proponentes do biodeterminismo racial. Essas idéias são óbvias tanto nos trabalhos que publicaram em revistas médicas, assim como no papel que desempenharam no campo de saúde pública e de medicina legal.

Do primeiro grupo destaca-se o psiquiatra Raimundo Nina Rodrigues, o qual, e de acordo com o nosso ponto de vista, teve não só a distinção dúbia de ter inaugurado "o rigoroso estudo científico de considerável parte da população afro-brasileira, mas também de ter iniciado uma tradição na psiquiatria brasileira de estudar os negros através de uma perspectiva racial" (Azevedo, 1963, pp. 402-4).

Nos primeiros anos da década de 1890, Nina Rodrigues foi designado para um cargo na Faculdade de Medicina da Bahia, fato que o aproximou de grupos médico-legais e médico-psicológicos dos Estados Unidos, França e Itália, que claramente o influenciaram. Numa longa série de livros e trabalhos publicados a partir de 1890, ele declarou que a inferioridade da raça negra era um fato científico e rejeitou a noção de que os negros pudessem se igualar às raças superiores. Além do mais, afirmou que esta inferioridade influenciava tanto o comportamento social que propôs que fosse dado o status de criança aos negros (tanto quanto aos índios), e que ficassem sob a tutela do estado, no âmbito do sistema penal brasileiro. Citou também o biólogo suíço Louis Agassiz, no que dizia respeito à miscigenação, quando predisse que no Norte tropical do Brasil o "sangue negro" triunfaria sobre o "sangue branco" (Azevedo, op. cit.).

Aqui temos então a primeira teoria racista elaborada por um médico brasileiro, teoria esta parecida com outras bastante populares na América 
do Norte e Norte da Europa. Note-se, porém, que Rodrigues não exerceu tanta influência em outros médicos do Brasil, mesmo se considerarmos que a crise de saúde dos negros estava no auge, quando ele escreveu seus trabalhos. Ele causou impressão, isto sim, em seus colegas de profissão, os psiquiatras, e o resultado foi que a Escola Bahiana de Medicina Legal manteve-se ativa até hoje, através de seus colegas e discípulos. Entres estes distinguiram-se os psiquiatras Henrique Roxo, Franco da Rocha, Juliano Moreira e, mais tarde, Ulysses Pernambucano, Oscar Freire e Afrânio Peixoto.

Tomemos Franco da Rocha como exemplo. Em 1896, ele escreveu um longo artigo sobre a insanidade dos negros, atribuindo-a a uma evolução incompleta do cérebro negro e considerando-a como um traço permanente e hereditário (apud Homem de Mello, 1904, p. 410). Uma vez mais, em um artigo, Franco da Rocha (1911, p. 459) afirmou que

Os negros no Brasil foram elevados pela influência social da religião católica predominante. Na sua maioria, contudo, a "mentalidade" negra é baixa, quando comparada à mentalidade "branca", levandose em conta que há exceções. (Ele acrescentou que) por causa da inferioridade psíquica dos negros suas aspirações são limitadas e tais aspirações ainda mantêm-se a um nível social muito baixo, não os encorajando a lutar pela vida de maneira muito intensa.

O dr. Franco da Rocha concluiu que os negros eram, então, incapazes de se adaptar à sociedade civilizada.

O dr. Henrique Roxo (1939, pp. 71-8), outro psiquiatra, chegou a conclusões semelhantes: "Entre a raça negra, o cérebro não evoluiu completamente e este traço meioprágico (sic) (de um lado) é transmitido por herança (e de outro lado) os casos de mania são relativamente raros entre indivíduos daquela raça fato substanciado por nossas estatísticas e fruto de nossa observação."

No mesmo trabalho, que aliás foi publicado em 1904 no BrasilMédico, o dr. Roxo declara que "(os negros) não usam seu cérebro tanto quanto os brancos, já que os brancos procuram elementos para os guiar em direção à vitória na competição pela vida".

Outros psiquiatras, tanto os contemporâneos como os discípulos de Nina Rodrigues, referem-se aos negros da mesma maneira. Seus trabalhos continuam a tradição iniciada pelo seu mestre de se dedicarem a análises sobre os negros nos moldes do biodeterminismo racial. ${ }^{17}$

O segundo grupo que emergiu da profissão médica e que adere a uma interpretação racista sobre a morbilidade e mortalidade negra foi a Sociedade de Eugenia, fundada em São Paulo na segunda década do século XX. Esposaram as idéias de Francis Galton (1822-1911), conhecido como 'pai da eugenia', que em Gênio hereditário (1869) procurou mostrar que características mentais eram herdadas da mesma maneira 
que traços físicos. A primeira edição da revista dessa sociedade, Anais da Eugenia , foi publicada em São Paulo em 1919 e continha dois trabalhos pródigos em jargão racial darwinista: um de autoria de Rubião Meira, e o outro, de Renato Kehl. Os dois trabalhos já haviam sido publicados na Gazeta Clinica de São Paulo, em 1918.

No artigo, o dr. Rubião Meira escreveu sobre a doença negra e mortalidade depois da abolição no Brasil, com termos muito similares aos usados pelos médicos sulistas e uns poucos nortistas que interpretaram a crise de saúde negra no período após a escravidão nos Estados Unidos:

Liberdade foi a causa da decadência, a ruína, a destruição daquela raça que até então (fim da escravatura) havia sido trabalhadora e cheia de vitalidade, construtiva e forte. Sem a educação suficiente para o conhecimento das obrigações que a liberdade traz consigo, sedentos de usufruir a própria autonomia ao máximo, atiraram-se ao caos existencial, com todas as suas paixões e vícios, e em poucos anos, o alcoolismo, a tuberculose e a sífilis os levou aos montes às camas dos hospitais, e aos cubículos dos sanatórios.

O dr. Rubião Meira, então, acreditava tanto na falta de habilidade dos negros em sobreviver por si mesmos após a liberdade, que predisse a sua extinção como raça. Ele foi também (e talvez não seja surpresa, uma vez que era um conhecido "eugenista") um proponente da causa do embranquecimento:

A raça negra, você o sabe tão bem quanto eu, está desaparecendo gradualmente, ... tornando-se extinta, e há cidades neste país onde raramente se acham negros, estando eles a ser substituídos por imigração estrangeira . Estrangeiros têm nos dado toda sua energia, trabalhando arduamente, batalhando com extraordinário fervor, elevando nossa nação, modificando nosso caráter, contribuindo sem sombra de dúvida para nosso progresso

trabalho destes dois grupos de médicos continua a ser o exemplo mais vivo da influência das idéias do racismo científico europeu em geral, e à eugenia em particular, na comunidade médica no Brasil. Ao adotarem os preceitos do biodeterminismo racista, estes psiquiatras e eugenistas demonstram, muito eloqüentemente, que não foi por falta de informação que a comunidade médica brasileira não fez o mesmo. E, no entanto, como vimos, até o final da Primeira Guerra Mundial, a maioria dos médicos manteve-se impermeável ao racismo científico e adotou primordialmente uma posição de caráter ambiental em sua visão da crise de saúde do Brasil. 


\section{Democracia racial ou racismo mascarado?}

Nas primeiras décadas do século XX, as cabeças pensantes no Brasil devem ter se debruçado sobre o lugar que o negro deveria ocupar na sociedade agora que era cidadão livre. Em concorrência a essas conversas de salão (essas preocupações só se podem ler nas entrelinhas das revistas médicas consultadas) estariam inquéritos sobre o balanço do desejado embranquecimento da nação.

Simultaneamente, os médicos brasileiros, liderados por Oswaldo Cruz, eliminaram a febre amarela e a varíola no Rio, forçando o declínio dessas doenças no resto do país. A praga foi despachada de vez. Concomitantemente, a estes avanços, deu-se também o embelezamento do Rio, complementado por projetos sanitários ambiciosos, também estendidos a outras cidades do país. Tais empreendimentos melhoraram a imagem do Brasil no exterior e dentro do país (Cooper, 1976; Needell, 1987).

É possivel teorizar que os médicos brasileiros, trabalhando através de órgãos públicos de saúde pública, tentavam implementar o ideal de embranquecer a nação, ideal este almejado e perseguido pela elite, desde a virada do século. Convém notar também que, enquanto uma imagem racional de saúde era cultivada, havia uma crise de saúde entre negros e pobres. A tuberculose, a sífilis, a pneumonia, as doenças que estavam matando os negros, continuavam grassando sem atenção governamental e médica. Por outro lado, aquelas doenças que atingiam ou tinham potencialidade de atingir ou matar os brasileiros brancos ou imigrantes europeus recebiam não só prioridade como também inteira atenção. ${ }^{18}$

Ainda assim, todo esse projeto não se desenvolveu muito além do planejamento. Mas, pode-se teorizar que os médicos usavam a eugenia como um meio de alcançar posições de poder. Assim, a esperança de purificação da raça no Brasil, exposta por Renato Kehl (1918, pp. 2013) através da aplicação da eugenia - "a verdadeira religião da humanidade" - jamais se concretizaria.

De qualquer forma, foi o ideal de embranquecimento que sobreviveu quando a intelligentsia no Brasil passou do "racismo científico prevalecente antes de 1914" para "a filosofia social-ambiental predominante depois de 1930". Neste período, parte da elite intelectual assumiu uma atitude que levava em conta o condicionamento ao meio ambiente nas questões raciais. Anteriormente, essa era a atitude exclusiva da classe médica.

Ainda assim, ironicamente, enquanto a maior parte dos brasileiros cultos nos idos de 1930 houvesse negado o racismo científico, os médicos brasileiros pareciam ter descoberto raça como variável importante na medicina, pois nas décadas de 1930 e 1940 as revistas médicas atolaramse com trabalhos sobre as ditas doenças dos negros. ${ }^{19}$

Verifica-se que os médicos brasileiros começavam a se preocupar com as doenças dos negros. Talvez porque finalmente eles tivessem 
sido movidos pela persistência da crise da saúde entre os negros, ou assumido sem subterfúgio o ideal de embranquecimento. Pois, na concepção brasileira, a eugenia foi vista como um tipo de engenharia que não somente iria ajudar no embranquecimento do país, mas, junto com o processo de eliminação da raça negra, iria também eliminar as muitas doenças que a infestavam.

É certo que, a partir da década de 1940, a tuberculose, a sífilis, as verminoses, o beribéri, a doença de Chagas, a lepra, o alcoolismo e quase todas as doenças da pobreza eram agora vistas como doenças dos negros e não foram alvo de campanhas de saúde (Meira, 1919, pp. 74-9).

\section{Conclusão}

Os psiquiatras da Bahia e os higienistas do Rio de Janeiro e de São Paulo constituíam exceções na comunidade médica brasileira ao abraçarem as teorias dos cientistas racistas do Norte da Europa e dos Estados Unidos no final do século XIX e primeiras duas décadas do século XX. Não há dúvida de que o trabalho destes dois grupos de médicos continuam a ser o exemplo mais vivo da influência das idéias do racismo científico europeu em geral, e da eugenia em particular, na comunidade médica no Brasil.

De qualquer modo, no caso dos psiquiatras e eugenistas no princípio do século XX ou, mais tarde, no caso da comunidade médica mais ampla, ao adotarem os preceitos do "darwinismo racial", da eugenia, e de outras teorias com matizes racistas variados, o que podemos dizer é que o total envolvimento dos médicos na saúde pública resulta em uma tese de branqueamento de duas partes. A primeira diz que a natureza sexual do homem estaria destinada a acelerar o processo de contínua mistura de brancos e negros e as novas nuanças de raça outra vez misturadas até que todos os negros desaparecessem. Este aspecto da tese de embranquecimento sofreu o ataque de intelectuais como Abdias do Nascimento. Ele a denunciou como a forma mais gritante de racismo e como um genocídio deliberado.

Ainda assim, o termo genocídio talvez seja mais aplicável à segunda fase da tese de branqueamento-eliminação, em vez de mistura, pois concluímos que a alta mortalidade sofrida pelas classes excluídas das políticas de saúde pública durante todo o século XX seria uma forma indireta de obter o embranquecimento do Brasil. É verdade que desde meados do século XX teses sobre o embranquecimento saíram de moda. Mas é possível ver que este processo prossegue a todo vapor. Hoje, as populações pobres (onde se concentra a maioria dos descendentes dos negros africanos em geral), quer no Nordeste quer nas favelas das grandes cidades, continuam sofrendo dos índices mais altos de morbidade e mortalidade. Em flagrante contraste, as elites (quase exclusivamente brancas) do Rio de Janeiro, São Paulo, Brasília, Recife e Bahia mantêm 
um dos mais altos padrões de vida do mundo. Talvez o conceito dos médicos que defendem a tese do embran-quecimento paulatino no Brasil, através da extinção da população "pobre" pela morte, tenha se tornado parte da vida cultural e institucional do país.

\section{$\mathcal{N O T A S ~}$}

${ }^{1}$ Em outro trabalho, submetido à publicação pela CLIO, abordo o debate intelectual sobre a natureza das relações raciais no Brasil.

${ }^{2}$ Será coincidência esta ter sido a data do início da era Vargas no Brasil e do triunfo das idéias políticas e raciais do nacionalsocialismo na Europa e na América Latina?

${ }^{3}$ Estas foram as doenças que afetavam populações de descendência africana na América do Norte e nas quais os médicos basearam seus estudos sobre as diferenças biológicas das raças.

${ }^{4} \mathrm{Na}$ nossa opinião, o termo pobre pode ser visto como um eufemismo para a população descendente de africanos.

${ }^{5}$ É preciso sublinhar que o dr. Wücherer não foi o primeiro médico que indicou a pobreza como causa principal da doença, mas seu estudo foi o primeiro dedicado em grande profundidade e exclusivamente à tuberculose no Brasil. Duas teses da Faculdade de Medicina da Bahia de 1852, nomeadamente a de Asprigio Proença (p. 31), e a de J. P. Corrêa de Freitas (p. 28), consideraram a tuberculose, respectivamente, como uma doença da "classe indigente" e "da classe mediana". J. R. Lima Duarte (1849, p. 20) também notou que "as senzalas estão cheias de umidade; as paredes e o chão prenhes com ela". Lima Duarte achava que a umidade e a falta de ventilação resultavam em tuberculose, uma doença que matava os escravos já nas senzalas.

${ }^{6}$ Alves da Silva (1878-79, pp. 42, 47-9) também colocou que a pobreza e a dieta deficiente em nitrogênio (termo contemporâneo para proteínas) não eram as únicas causas da suscetibilidade à tuberculose. Como Wücherer na década anterior, este médico também acusou o clima como causa dessa doença.

${ }^{7}$ Outro problema apontado por este médico foi que a saúde dos pais na concepção seria um fator que tornaria a escrófula uma doença hereditária (Rocha Lima, 1887, pp. 106-7).

${ }^{8} \mathrm{O}$ dr. Augusto Azevedo Sodré (1918, p. 26), uma década e meia mais tarde, ligou a diminuição nos índices de mortalidade em geral com o declínio nas percentagens da população negra nessa cidade. Na verdade, segundo Herbert Klein, se por um lado, "entre 1872 e 1876 , aproximadamente 25.711 escravos tenham sido importados para as províncias do Rio de Janeiro e de São Paulo ... as zonas centrais do café no Brasil” (1971, pp. 567-9), por outro lado, centenas de milhares de imigrantes europeus incharam a população dessas regiões. O historiador H. C. Haring (1958, pp. 100-5) afirma que, só de italianos, chegaram à província de São Paulo 97 mil em 1889, e 108 mil em 1891. A historiadora Kim D. Butler (1998, p. 71, n. 19) cita estatísticas do sociólogo Florestan Fernandes e do historiador norte-americano Thomas Holloway para sublinhar um argumento semelhante, nomeadamente de que a percentagem (mas não os números) dos negros na cidade de São Paulo diminuiu devido ao aumento dos imigrantes europeus.

${ }^{9}$ Ver Sílvio Romero (1969, p. 55, 95, 190); Cruz da Costa (1964, pp. 182-202); Maciel de Barros (1959, pp. 132, $136,145$. 6, 166-9, 183-4). Maciel de Barros (op. cit., p. 68) considera Tito Lívio de Castro "o mais brilhante de um grupo de jovens médicos darwinistas do Rio de Janeiro".

${ }^{10}$ Ver, por exemplo, Lima (1865, pp. 146-51; 1867, pp. 172-6). Collas (1867, pp. 151-5) declarou que o ainhum não era uma doença comum só entre os negros, mas também entre os índios. Costa (1875); Wücherer (1874); Guimarães (1876).

${ }^{11}$ Ver também as listas de revistas médicas recebidas do estrangeiro e publicadas periodicamente na Gazeta Médica da Bahia e no Brasil-Médico, a partir de 1871 (data da publicação de Descent of man de Charles Darwin).

12 Quando fazemos esta colocação, referimo-nos aos intelectuais brasileiros que integraram não só o pensamento de Darwin, como o de outros intelectuais europeus, como, por exemplo, do seu grande admirador e discípulo alemão, Ernst Haeckel, na formulação da tese de branqueamento. Ver Costa (1964, pp. 186, 197, 360, n. 48); Maciel de Barros (1986, pp. 134-5, 145-8; este autor usou freqüentemente a expressão "darwinismo de matiz haeckeliano", ao abordar este grupo de intelectuais); Azevedo (1963, p. 425).

$13 \mathrm{O}$ dr. Plácido Barbosa lamentou que o índice de mortalidade de tuberculose no Rio de Janeiro fosse mais alto do que o de trinta maiores cidades do mundo, entre as quais Londres, Berlim, Dublin, Chicago, Nova York e Buenos Aires (I: 251)

14 Azevedo Sodré (1918, pp. 24-9). As cidades que enumerou foram Rio de Janeiro, Niterói, Bahia, Campos, Recife, Santos e Campinas.

15 "Racismo científico" é um termo usado para as asserções e teorias racistas que os intelectuais do século XIX acreditavam poder ser corroboradas pela ciência. 
16 Silveira (1939, p. 76). Ver Dubos (1952, p. 185), e Torchia (1975, p. 152), para argumentos sobre a evolução da tuberculose nas populações humanas.

17 Azevedo (1963, pp. 402-4). Russell-Wood (1982, p. 6) afirmou que o dr. Nina Rodrigues "foi superinfluenciado pelos estudos pseudocientíficos de Lombroso e Ferri”. Também Nina Rodrigues (1904, pp. 102-38) fez diversas referências à "escola psiquiátrica francesa" e à "escola psiquiátrica italiana" e citou diretamente as asserções de Lombroso (que considerou seu mentor eminente) assim como as de Tanzi, Lacassgne e outros que se pronunciaram sobre a inferioridade mental dos negros. Nina Rodrigues (1894, p. 44) adiantou que os negros nunca seriam mentalmente iguais aos brancos e que sua inferioridade mental era hereditária e estava comprovada pela ciência. Ver também Franco da Rocha (1911, p. 459).

18 É interessante notar que o professor norte-americano Joel Williamson (1984, p. 450) fez uma análise semelhante para o Sul dos Estados Unidos, quando afirmou que "as grandes campanhas de saúde pública que se iniciaram em 1906 contra a tuberculose, a febre amarela, hookworm, e pelagra, assim como as campanhas para melhoria das condições sanitárias ... foram ... uma das manifestações mais óbvias da preocupação das elites pelas populações brancas". Por outro lado, e diferente do que aconteceu no Brasil, "doentes negros foram incluídos nestas campanhas".

19 Skidmore (1993, p. 203). Lembramos que nossa análise é baseada na leitura de revistas médicas brasileiras publicadas entre 1866 e 1945 . Ver também Kiple (1987).

\section{REFER̂ETCIAS BIBLIOGRÁFICAS}

Alves da Silva, Guilherme

$1878-79$

Azevedo, Augusto

César de Miranda

1976

Azevedo, Fernando de 1963

Azevedo Lima 1905

Azevedo Sodré,

Augusto

1918

Barbosa, Plácido 1917

Biddiss, Michael (org.) 1979

Butler, Kim $\mathcal{D}$.

1998

Carneiro, $\mathcal{H}$. 1917

Carneiro, J. F. Domingues

1934

Collas, $\mathcal{A}$. 1867

Cooper, Donald $\mathcal{B}$.

Cruz da Costa, João 1964

Dias, Mariano $R$. 1907
Da influência dos climas sobre o desenvolvimento da tísica pulmonar: quais as condições higiênicas mais favoráveis ao tratamento desta moléstia?. Tese, Rio de Janeiro, Faculdade de Medicina.

'Conferências populares: darwinismo'. Arquivos do Instituto Histórico e Geográfico Brasileiro, Coleção Lima Drummond.

A cultura brasileira: introdução ao estudo da cultura no Brasil. $4^{\text {a }}$ ed., Brasília, s. e.

'Contribuição ao histórico da luta contra a tuberculose no Brasil'. Brasil-Médico, XIX, I: 223-4.

A luta antituberculosa.

Rio de Janeiro, s. e.

'O problema da tuberculose na cidade do Rio de Janeiro'. Brasil-Médico, XXXI, III: 270-1.

Images of race.

Nova York, s. e.

Freedoms, given, won: post-abolition Afro-Brazilians in São Paulo and Salvador. Baltimore, Johns Hopkins University Press.

'A criança tuberculosa no Rio de Janeiro'.

Archivos Brasileiros de Medicina, VII.

'Clima e tuberculose'.

Brasil-Médico, XLVIII.

'Sobre a moléstia descrita com o nome de ainhum, observada nos índios'. Gazeta Médica da Bahia, II.

'Brazil's long fight against epidemic diseases, 1849-1917, with special emphasis on yellow fever'. Bulletin of the New York Academy of Medicine, LI, pp. 672-96.

A history of ideas in Brazil.

Berkeley, University of California Press.

Da tuberculose e o casamento.

Tese, Rio de Janeiro, Faculdade de Medicina. 
Duarte, J. R. Lima

1849

Dubos, René e Jean

1952

Esteves, Henrique

1939

Franco da Rocha

1911

Freitas, J. P. Correia de 1852

Freitas, Octavio de 1940

Freitas, Octavio de 1939

Godinho, Victor 1904

Guimarães, José

Ferreira 1876

Haring, C. $\mathcal{H}$. 1958

Homem de Mello 1904

Kehl, Renato 1919

Kiple, Dalila de Souza 1987

Klein, Herbert

1971

Kuper, Leo (org.)

Lima, Francisco da Silva 1865-67

Maciel de Barros 1986

Martins, Costa

1875

Medeiros, Amaury 1920

Meira, Rubião

1919

Motta, Orlando Cabral 1940

Needell, Jeffrey

s. d.

Nina Rodrigues, Raimundo 1904
Ensaio sobre a higiene da escravatura no Brasil.

Tese, Rio de Janeiro, Faculdade de Medicina.

The white plague: tuberculosis, man an society. Boston, Little Brown.

'A tuberculose pulmonar do preto no Pará'.

Revista Brasileira de Tuberculose, VIII.

'Contribuition à l'étude de la folie dans la race noire'.

Revista Médica de São Paulo, XIV.

Considerações gerais sobre algumas moléstias mais freqüentes na Provincia do Pará. Tese, Salvador, Faculdade de Medicina.

'Valor das raças sobre a freqüência e as formas da tuberculose em Pernambuco'. Jornal de Medicina de Pernambuco, XXXVI.

'Incidência de tuberculose no preto de Pernambuco'. Revista Brasileira de Tuberculose, VIII.

'A tuberculose do ponto de vista social'.

Revista Médica de São Paulo, vol. VII.

'Do ainhum'.

Revista Médica do Rio de Janeiro.

Empire in Brazil: a new world experimental with monarchy.

3a ed., Cambridge, Massachusetts.

Comentário sobre 'Perturbações mentais dos negros no Brasil', de Franco da Rocha. Revista Médica de São Paulo, VII.

'Darwinismo social e eugenia'.

Anais de Eugenia, I, pp. 177-83.

Darwin and medical perceptions of blacks in the United States and Brazil. Tese de doutoramento, Ohio, Bowling Green State University.

'The internal slave in nineteenth century Brazil: a study of slave importations into Rio de Janeiro in 1852'.

The Hispanic American Historical Review, LI, pp. 567-9.

Race, science an society.

Paris, Unesco.

'Estudo sobre o ainhum, moléstia ainda não descrita'.

Gazeta Médica da Bahia, I, II.

A ilustração brasileira e a idéia de universidade.

São Paulo, Edusp.

Ainhum: estudo sobre a moléstia conhecida sob esta denominação.

Rio de Janeiro, s. e.

Um grito de alarme: o problema da tuberculose no Brasil.

Rio Janeiro, s. e.

'Fatores de degeneração da nossa raça: meios de combatê-los'.

Anais da Eugenia, I, pp. 47-64.

'Tuberculose pulmonar de forma cavitária, basilar no homem de cor: ensaio de estudo patogenético’. Brasil-Médico, LVI.

'Popular responses to reform: the so-called Revolta da Vacina de 1904'. s. 1.

'Atavismo psíquico e paranóia'.

Revista Médica de São Paulo, VIII. 
Nina Rodrigues, Raimundo

1894

Penna, Belisário

1918

Proença, Asprigio 1852

Rebello, Eugenio

Guimarães

1869

Richet, $C$.

1873

Rocha Lima,

Francisco da. 1887

Romero, Silvio 1900

Roxo, Henrique 1937

Roxo, Henrique maio 1904

Russe[l-Wood, A. J. R. 1982

Sant'Anna, Eurydice Pires de e Teixeira, Rudolfo (orgs.) 1984

Silveira, José da 1939

Skidmore, Thomas 1993

Torchia, Marion 1975

Vita, Washington (org.) 1969

Williamson, Joel 1984

Wücherer, Otto 1874

Wücherer, Otto 1869-1868

Wücherer, Otto 1866

Xavier Sigaud, Joseph François 1844
As raças humanas e a responsabilidade penal.

Salvador. s. e.

Saneamento do Brasil.

Rio de Janeiro, Editora dos Tribunais.

Ensaio de estatística médica da cidade de Salvador.

Tese, Salvador, Faculdade de Medicina da Bahia.

As raças humanas descendem de uma só origem?.

Tese, Salvador, Faculdade de Medicina.

'Do estudo da antropologia'.

Gazeta Médica da Bahia, VII.

Da escrófula em sua relação com a tuberculose.

Tese, Salvador, Faculdade de Medicina da Bahia.

Explicações indispensáveis.

Prefácio a Vários escritos de Tobias Barreto. Rio de Janeiro.

'Novas considerações sobre as perturbações mentais nos negros do Brasil'.

Arquivos Brasileiros de Neuratria e Psiquiatria, XXII.

'Perturbações mentais dos negros no Brasil'.

Brasil-Médico, VII.

The black man in slavery and in freedom in Colonial Brazil.

Nova York, s. e.

Gazeta Médica da Bahia: indice cumulativo - 1866-1976.

Salvador, UFBA.

'Sobre as formas anatomoclínicas da tuberculose pulmonar nos negros na Bahia'. Arquivos do Instituto Brasileiro de Tuberculose, III.

Black into white: race and nationality in Brazilian thought. 2 ${ }^{\text {a }}$ ed., Durham, Duke University Press;

'The tuberculosis movement and the race question, 1890'. Bulletin of the History of Medicine, XLIV.

Silvio Romero: obra filosófica.

Rio de Janeiro, s. e.

The crucible of race: black-white relations in the American South since emancipation. Nova York, Oxford University Press.

'Um caso de ainjum: comunicação feita à Academia Imperial de Medicina do Rio de Janeiro'. Revista Médica do Rio de Janeiro.

'Sobre as causas da crescida freqüência da tísica pulmonar no Brasil e especialmente na Bahia'.

Gazeta Médica da Bahia, II, 1: 265-8; III, 2; 28-9, 290-3.

'A moléstia como parte do plano de criação'.

Gazeta Médica da Bahia, I.

Du climat et des maladies du Brésil.

Paris, s. e. 